\title{
Mide hiperplastik polipleri ve öncül lezyonlarının değerlendirilmesi
}

\author{
Evaluation of gastric hyperplastic polyps and their precursor lesions
}

\author{
(D) RIfat PEKSÖZ' , (DAli MIZRAK² \\ Muş Devlet Hastanesi ${ }^{1}$ Genel Cerrahi Bölümü, ${ }^{2}$ Patoloji Bölümü, Muş
}

Giriş ve Amaç: Mide poliplerinin yaklaşık \%75-90 kadarını hiperplastik polipler oluşturur. Kronik inflamasyon nedenli epitelin aşırı rejeneras yonuna bağlı, foveolar hiperplazi ve kronik gastrit sonrasında bu öncül lezyonlardan hiperplastik polipler oluşur. Bu çalışmada mide hiperplastik polipler ve öncül lezyonlarının Helicobacter pylori ile ilişkisi ve bu lezyonların intestinal metaplazi, atrofi durumlarının literatür bilgileri eşliğinde tartışılması amaçlanmıştır. Gereç ve Yöntem: Muş Devlet Hastanesi Endoskopi ünitesinde Ocak 2016-Ocak 2020 tarihleri arasında özofagogastroduodenoskopi yapılan 7903 hastadan endoskopik görünümü polipoid yapıda olan 172 hastanın histopatolojileri değerlendirildi. Hastaların yaşı, cinsiyeti, başvuru şikâyeti, polipoid görünümlü lezyonun yeri, lezyonların histopatolojik tipi kaydedildi. Bulgular: 172 hastaya polipektomi yapıldı. Hastaların 71'i erkek (\%41.2), 101'i kadın (\%58.8) olup, yaş ortalamaları $49.4 \pm 15$ (19-83) yıldı. Hastalar reaktif polipoid lezyonlar; foveolar hiperplazi 57 hasta, kronik gastrit 53 hasta ve gerçek polipoid 62 hasta (en sık hiperplastik polip 47 hasta \%75) olarak iki gruba ayrıldı. Polipoid görünümlü lezyonlar en fazla antrumda lokalize idi. Hastaların başvuru şikayeti her iki grupta en fazla dispepsi idi. Gerçek polip lezyonlarının çapı, reaktif polipoid lezyonların çapından istatistiksel olarak büyük saptandı ( $p<0.05)$. Helicobacter pylori oranı reaktif polipoid grupta istatistiksel olarak daha yüksek bulundu ( $p<0.05)$. intestinal metaplazi ve atrofi durumu açısından fark saptanmadı ( $p>$ 0.05). Sonuç: Hiperplastik polipler ve öncül lezyonlarının prekanseröz durumlar olan atrofi ve intestinal metaplazi oranları arasında anlamIı fark saptanmamıştır. Bu yüzden endoskopide saptanan lezyonlardan tanı ve displazinin varlığını saptamak için biyopsi alınmalı ya da eksize edilmeli ve Helicobacter pylori saptanan hastalar tedavi edilmelidir.

Anahtar kelimeler: Hiperplastik polip, foveolar hiperplazi, kronik gastrit, Helicobacter pylori

\section{GíRiş}

Gastrointesitinal sistemden lümene doğru uzanıp mukoza ya da submukozadan kaynaklanan proliferatif lezyonlar polip olarak tanımlanır. Gastrik polipler genellikle endoskopik işlem esnasında insidental olarak saptanan küçük ve asemptomatik lezyonlardır $(1,2)$. Midede en sık hiperplastik polip ve fundik gland polipleri görülür. Poliplerin midede yerleşimleri ve histolojik tipleri genellikle midedeki anatomik bölgelere göre farklılık göstermektedir. Hiperplastik ve adenomatöz polipler Helicobacter pylori

Illetişim: RIfat PEKSÖZ

Muş Devlet Hastanesi Genel Cerrahi Bölümü, Muş

E-mail: rifat-peksoz@hotmail.com
Background and Aims: Approximately $75-90 \%$ of gastric polyps are comprised of hyperplastic polyps formed by precursor lesions after foveolar hyperplasia and chronic gastritis due to excessive epithelial regeneration caused by chronic inflammation. In this study, we discuss the relationship between gastric hyperplastic polyps and precursor lesions and Helicobacter pylori as well as intestinal metaplasia and the atrophy states of these lesions in light of the literature. Material and Methods: Among 7,903 patients who underwent esophagogastroduodenoscopy at Muş State Hospital between January 2016 and January 2020, 172 with an endoscopic view of polypoid structures were included and histopathologically examined. Data including age, sex, admission complaint, location of the polypoid lesion, and histopathological type were recorded. Results: The patients [101 females (58.8\%); age, $49.4 \pm 15$ (19-83) years] underwent polypectomy. They were divided into the reactive polypoid group (57 patients with reactive foveolar hyperplasia and 53 with reactive chronic gastritis) and the actual polypoid group (62 patients; hyperplastic polyps in 47). Polypoid lesions were most often localized in the antrum. The most common complaint on admission was dyspepsia. The diameter of the actual polypoid lesions was significantly larger than that of the reactive polypoid lesions $(p<0.05)$. The rate of Helicobacter pylori infection was significantly higher in the reactive polypoid group than in the actual polyploid group $(p<0.05)$. There was no difference in terms of intestinal metaplasia and atrophy $(p>0.05)$. Conclusions: No significant differences were observed in the prevalence of intestinal metaplasia and atrophy or between the rates of atrophy and intestinal metaplasia (precancerous condition of the hyperplastic polyps and their precursor lesions). Therefore, biopsy or excision of endoscopically detected lesions should be performed to diagnose dysplasia. Patients should be treated for Helicobacter pylori.

Key words: Hyperplastic polyp, foveolar hyperplasia, chronic gastritis, Helicobacter pylori

(H. pylori) enfeksiyonunun sık olduğu yerlerde, fundik gland poliplerinden daha fazla görülmektedir $(2,3)$.

Mide poliplerinin yaklaşık \%75-90 kadarını hiperplastik polipler oluşturur (4). Kronik inflamasyon nedeniyle epitel aşırı rejenerasyona uğrar böylece polip öncülleri ve hiperplastik polipler oluşur $(5,6)$. Poliplerin çok büyük kısmını oluşturan hiperplastik polipler ve öncüllerini oluşturan polipoid görünümlü lezyonların karşılaştııımasını inceleyen geniş çaplı bir literatür çalışması henüz yoktur.

Peksöz R, Mizrak A. Evaluation of gastric hyperplastic polyps and their precursor lesions. The Turkish Journal of Academic Gastroenterology 2021;20:3-7. DOI: 10.17941/agd.927776

Geliş Tarihi: 20.10.2020 • Kabul Tarihi: 05.03.2021 
Bu çalışmada $H$. pylori görülme oranının yüksek olduğu Muş yöresinde yapılan endoskopik işlemlerde saptanan mide hiperplastik polipleri ve öncül lezyonlarının, H. pylori ile ilişkisi ve bu lezyonların intestinal metaplazi, atrofi durumlarının incelenmesi amaçlanmıştır.

\section{GEREÇ ve YÖNTEM}

Bu çalışma için Erzurum Bölge Eğitim ve Araştırma Hastanesi Etik Kurulu'ndan 2020/06-67 karar numarası ile onay alındı. Muş Devlet Hastanesi Endoskopi ünitesinde Ocak 2016-Ocak 2020 tarihleri arasında özofagogastroduodenoskopi (ÖGD) yapılan 7903 hasta retrospektif olarak incelendi ve endoskopik görünümü polipoid yapıda olan 172 hastadan alınan lezyonlar değerlendirildi. Hastaların yaşı, cinsiyeti, başvuru şikâyeti, polipoid görünümlü lezyonun yeri, lezyonların histopatolojik tipi kaydedildi. Lezyon sınıflaması için Odze ve Turner'in histopatolojik sınıflaması rehber olarak kullanıldı (Tablo 1) (6). Lezyonlar gerçek polipler ve reaktif polipoid lezyonlar olarak iki ana gruba ayrıldı. Hiperplastik polip dışı gerçek polipler çalışma dışı bırakılmış olup aynı hastada birden fazla hiperplastik polip saptandığında ise analizler için ortalama değer alındı. Hiperplastik polip ve öncül lezyonları olan kronik gastrit ve foveolar hiperplazideki $H$. pylori varlığı, atrofi ve intestinal metaplazi değişiklikleri karşılaştırıldı. İslem öncesi hasta ve yakınlarına işlem ile ilgili bilgi verildikten sonra hasta rıza onam formu imzalatıldı. İşlem öncesi gün diyet verildikten sonra hastaların en az 8 saat oral yoldan beslenmesi kesildi. Işlem esnasında hastalar monitörize edildi ve oksijen desteği altında oral lokal anestezi (\%10 lidokain sprey) uygulanarak işlem yapıldı. $5 \mathrm{~mm}$ altındaki polipler forseps ile, $5 \mathrm{~mm}$ üstündeki polipoid lezyonlar snare ile eksize edildi. İstatistiksel analiz için SPSS 21.00 paket programı kullanıldı. Sonuçlar kategorik değişkenler için sayı, yüzde sürekli değişkenler için ortalama \pm standart sapma olarak belirtildi. Grup ortalamalarının karşılaştırımasında normal dağı̆ım gösteren değişkenler için Student $t$ testi, normal dağılım göstermeyen değişkenler için Mann-Whitney $U$ testi kullanıldı ve $p<0.05$ anlamlı değer olarak kabul edildi.

\section{BULGULAR}

Endoskopi ünitemizde ÖGD yapılan 7903 hastada saptanan lezyonların 3950'sinden (\%50) biyopsi alındı, 172'sine (\%2.2) polipektomi yapıldı. Toplamda 186 polipoid lezyon eksize edildi. Hastaların 71'i erkek (\%41.2), 101 'i kadın (\%58.8) olup, yaş ortalamaları $49.4 \pm 15$ (1983) yıldı.

Endoskopik görünümü polipoid yapıda olan reaktif polipoid lezyonların 110'unun (\%63.9) histopatolojisi, foveolar hiperplazi (57) veya kronik gastrit (53) olarak değerlendirildi.

Gerçek polip olan lezyonlar olarak; en yaygın tip hiperplastik polip 47 hastada (\%75) 56 tane, epitelyal polip 8 hastada (\%13) 11 tane, hamartamatöz polip 4 hastada 5 tane, inflamatuvar polip 2 hastada 3 tane ve miscellaneous polip 1 hastada olmak üzere toplamda 76 gerçek polip tespit edildi. Hastaların \%58 kadarı kadın, \%62'si 50 yaş üzeri olup, pik yapılan aralık 5-6. dekat arası (\%36) idi.

Hiperlastik lezyon saptanan hastalarının yaş ortalaması $52.8 \pm 14.8$ (19-83) yaş ve 16 erkek 31 kadın hasta idi. Reaktif polipoid lezyonların yaş ortalaması $47.4 \pm 15$ (20-

Tablo 1. Mide poliplerinin histopatolojik sınıflaması

\begin{tabular}{|c|c|c|}
\hline Hiperplastik Polipler & Miscellaneous Polip ve Polip Benzeri & Epitelyal Polipler \\
\hline Hiperplastik polip & Lezyonlar & Adenom \\
\hline Polipoid foveolar hiperplazi & Ksantom & Pilorik bez adenom \\
\hline Foveolar polip & Histiyositozis-X & Polipoid karsinom \\
\hline Gastritis sistika polipoza/profunda & Yalancı taşlı yüzük hücreli karsinoma in & Oksintik bez polipi \\
\hline Menetrier hastalığı & situ & Karsinoid tümör \\
\hline \multirow{3}{*}{$\begin{array}{l}\text { İnflamatuvar Polipler } \\
\text { Inflamatuvar retansiyon polibi } \\
\text { Polipoid gastrit }\end{array}$} & \multirow{4}{*}{$\begin{array}{l}\text { Granülom } \\
\text { Amiloidozis } \\
\text { Kalsiyum depozitleri } \\
\text { Hemosiderosis }\end{array}$} & Metastatik karsinom \\
\hline & & Non-Epitelyal Polipler \\
\hline & & İnflamatuvar fibroid polip \\
\hline \multirow{5}{*}{$\begin{array}{l}\text { Hamartamatöz Polipler } \\
\text { Fundik gland polipleri } \\
\text { Peutz-Jeghers polipozis } \\
\text { Jüvenil polip } \\
\text { Cronkhite-Canada sendromu-ilişkili polip }\end{array}$} & & İnflamatuvar miyofibroblastik tümör \\
\hline & Heterotopik Polipler & Gastrointestinal stromal tümör \\
\hline & Heterotopik pankreatik polip & Vasküler tümör \\
\hline & Pankreatik asiner metaplazi & Lenfoid hiperplazi \\
\hline & Brunner bez nodülleri & Lenfoma \\
\hline
\end{tabular}


82) yıl idi. Bu grupta 45 erkek, 65 kadın hasta bulunmaktaydı. Hiperplastik polipler ve reaktif polipoid lezyonların yaşları arasında istatistiksel olarak anlamlı fark saptanma$d_{\imath}(p>0.05)$.

Hastaların poliklinik başvuru şikayetine bakıldığında, reaktif ve gerçek polipoid lezyonlu hastalarda görülen en fazla şikayet dispepsi idi (Tablo 2).

Polipoid görünümlü lezyonlar midede en fazla antrumda lokalize olarak saptandı (Tablo 3).

Gerçek polip lezyonlarının çapı $4.8 \pm 1.5 \mathrm{~mm}$, reaktif polipoid lezyonların çapı $3.7 \pm 0.66 \mathrm{~mm}$ olup, iki grup arasında istatistiksel olarak anlamlı fark saptandı ( $p<0.05)$.

Lezyonların H. pylori, intestinal metaplazi, atrofi durumları karşılaştırıldı (Tablo 4).

H. pylori oranı reaktif polipoid grupta istatiksel anlamlı olarak daha yüksek saptandı ( $p<0.05)$. Intestinal metaplazi ve atrofi durumu açısından gruplar arasında anlamlı bir fark saptanmadı ( $p>0.05)$.

\section{TARTIŞMA}

Polipoid lezyonlar üst gastrointestinal sistem endoskopileri sırasında \%0.6-3.8 oranında ve genellikle rastlantısal olarak saptanır $(2,7)$. Polipler genelde asemptomatik olmakla birlikte en sık başvuru şikâyeti dispeptik şikayetler olup karın ağrısı, kanama, anemi ve mide çıkış obstrüksiyonu diğer şikayetlerdir $(2,8,9)$. Hastalarımızın büyük kısmı literatüre benzer şekilde \%47'si dispepsi, \%29'u karın ağrısı şikayetleriyle başvurdu.

Çalışmamızda poliplerin sıklığı \%0.78 olup literatüre göre kısmen daha düşük oranda saptanmıştır. Bunun nedeni birçok çalışmada yüksek oranda görülen foveolar hiperplazi gibi polip öncüllerinin polip grubuna dahil edilmesinden kaynaklanmaktadır $(3,9)$.

Gastrik polipler midenin her tarafında görülebilir. Yapılan bir çalışmada mide poliplerinin \%51'i antrum, \%35'i korpus, \%8'i fundus, \%6'sı kardiyada saptanmıştır (10). Çalışmamızda gerçek mide poliplerinin \%74'i antrumda, \%19'u korpusta, \%3'ü fundusta görüldü.

Tablo 2. Hastaların başvuru şikayetleri

\begin{tabular}{|lcc|}
\hline Hastanın Şikayeti & $\begin{array}{c}\text { Gerçek Polipoid Lezyona } \\
\text { Sahip Hastalar (n, \%) }\end{array}$ & $\begin{array}{c}\text { Reaktif Polipoid Lezyona } \\
\text { Sahip Hastalar (n, \%) }\end{array}$ \\
\hline Dispepsi + reflü & $29(\% 47)$ & $62(\% 56)$ \\
\hline Karın ağrısı & $18(\% 29)$ & $33(\% 30)$ \\
\hline Malignite taraması & $6(\% 10)$ & $3(\% 56)$ \\
\hline Anemi & $4(\% 6)$ & $3(\% 3)$ \\
\hline Diğer semptomlar & $5(\% 8)$ & $9(\% 3)$
\end{tabular}

Tablo 3. Gastrik polipoid lezyonların lokalizasyonu

\begin{tabular}{|lcc|}
\hline Lokalizasyon & $\begin{array}{c}\text { Gerçek Polipoid Lezyona } \\
\text { Sahip Hastalar (n, \%) }\end{array}$ & $\begin{array}{c}\text { Reaktif Polipoid Lezyona } \\
\text { Sahip hastalar (n, \%) }\end{array}$ \\
\hline Antrum & $46(\% 74)$ & $105(\% 10)$ \\
\hline Korpus & $12(\% 19)$ & $3(\% 3)$ \\
\hline Prepylorik alan & $2(\% 3)$ & $2(\% 2)$ \\
\hline Fundus & $2(\% 3)$ & 0
\end{tabular}

Tablo 4. Hiperplastik, foveolar hiperplazi, kronik gastrit karşılaştırılması

\begin{tabular}{|lccc|} 
& Helicobacter pylori & İntestinal Metaplazi & Atrofi \\
\hline Hiperplastik polip & $\% 63$ & $\% 19$ & $\% 15$ \\
\hline Foveolar hiperplazi & $\% 83$ & $\% 25$ & $\% 14$ \\
\hline Kronik gastrit & $\% 82$ & $\% 25$ & $\% 7$
\end{tabular}


Mide polipleri patolojik sınıflaması için Dünya Sağlık Örgütü'nün, non-neoplastik, neoplastik, reaktif polipoid snıflaması olmasına rağmen pratik uygulamada genelde farklı sınıflamalar kullanılmaktadır. Birçok çalışmada olduğu gibi çalışmamızda da Odze ve Turner'in histopatolojik sınıflaması rehber olarak kullanıımışır $(6,11)$.

Mide poliplerinin çok büyük kısmını oluşturan hiperplastik polipler sıklıkla yaşlı insanlarda görülür ve 6. ve 7. dekadlarda pik yaparlar. Her iki cinste de eşit oranda görülürler (11). Çalışmamızda hiperplastik poliplerin \%66'sını kadınlar oluşturup hastaların \%62'si 50 yaş üzerinde ve pik yaş 5-6. (\%38) dekatlardadır.

Hiperplastik poliplerin histopatolojik özellikleri incelendiğinde \%85'den fazlası kronik gastrit zemininde oluşur. Bu lezyonlar doku hasarı ve enflamasyona aşıı bir mukozal cevap sonucu gelişirler $(12,13)$. Gastritin hasar süreçlerini başlattığı ve bu mukozal iyileşme yanıının foveolar hiperplazi ve polipoid hiperplazi fazlarından ilerleyerek hiperplastik polip oluşumuyla sonuçlandığı düşünülmektedir (6).

Foveolar hiperplazi ve polipoid görünümlü kronik gastrit, polipoid öncül lezyonlarıdır. Polip tanısı histopatolojik olarak konulur ve mideden lümene çıkıntı yapan her lezyona polip tanısı konulmamalıdır (3). Yapılan geniş çaplı bir çalışmada endoskopik işlem serisinde lezyonların \%48.8'i klasik epitelyal polip özelliklerine sahip bulunmuştur (14). Başka bir çalışmada gerçek polipoid lezyon oranı \%40 saptanmıştır (7). Çalışmamızda literatüre benzer şekilde gerçek polipler \%36, reaktif polipler ise \%64 (foveolar hiperplazi \%33, kronik gastrit \%31) oranında bulunmuştur.

Hiperplastik polipler midenin herhangi bir bölgesinde görülebilmesine rağmen en sık antrumda görülür. Hiperplastik poliplerin çoğu $1 \mathrm{~cm}$ 'den küçük olup \%50 kadarı 5 mm'nin altındadır (15). Çalışmamızda en sık antrumda görülmüş olup \%68 kadarı 5 mm'nin altında ve \%95 kadarı $1 \mathrm{~cm}$ 'nin altındadır. Hiperplastik poliplerin displaziye dönüşme riski \%1-20 arasında değişmektedir. Henüz evrensel bir fikir birliği olmasa da yaş önemli bir faktör olmakla birlikte 1,5 cm'nin altında displazi görülme durumu nadirdir (6).

Hiperplastik poliplerin atrofik gastrik ve $H$. pylori enfeksiyonu ile ilişkisi bilinmektedir. H. pylori enfeksiyonunun sık görüldüğü coğrafik yerlerde hiperplastik ve adenomatöz poliplerin fundik gland poliplerine göre daha sık olduğu görülmüştür. H. pylori enfeksiyonunun az görüldüğü, proton pompa inhibitörünün fazla kullanıldığı batı ülkelerinde ise fundik gland polipleri daha fazla görülmektedir $(2,11,16)$. H. pylori'nin mide mukozasına persistan kolo- nize olmasına bağlı olarak gastrit ve ülser gelişir. Hastaların \%1'inde süperfisyel atrofik gastrit gelişerek hücrelerde hasar oluşur ve zamanla mide kanseri gelişir (17). Çeşitli çalışmalarda $H$. pylori'nin eradike edilmesi ile hiperplastik poliplerin gerilediği gözlemlenmiştir. Ülkemizde yapılan çalışmalarda $\mathrm{H}$. pylori oranı batı ülkelerine göre daha yüksektir $(3,18)$. Hiperplastik poliplerin $\% 35-76$ 'sında $\mathrm{H}$. pylori bulunmuştur $(7,19)$. Çalışmamızda hiperplastik poliplerdeki H. pylori oranı \%63 olup literatüre göre kısmen yüksektir.

Intestinal metaplazi (IM) gastrik kansere yol açabilen bir prekanseröz lezyondur. Gastrik kanser gelişme riski 6 kat artabilmektedir (20). Yine mide mukozasında şiddetli atrofi olması daha fazla mide kanseri riski olarak görülmektedir (21). Yapılan çalışmalarda hiperplastik polipli hastalarda intestinal metaplazi oranı \%38 ve atrofik gastrit saptanma oranı \%8 olarak bulunmuştur (3). Bizim çaIışmamızda hiperplastik grupta intestinal metaplazi \%19, atrofik gastrit oranı \%15 bulunmuştur.

Karagülle ve arkadaşlarının yaptığı çalışmada reaktif ve gerçek polipoid lezyonlar arasında; $H$. pylori reaktif polipoid grupta anlamlı olarak daha yüksek saptanmıştır ancak atrofik gastrit, intestinal metaplazi mevcudiyeti açısından istatistiksel fark saptanmamıştır (7). Çalışmamızda gerçek ve reaktif polipoid lezyonlar arasında intestinal metaplazi ve atrofi oranları arasında anlamlı fark saptanmamıştır. Ancak bu konuda az sayıda literatür çalışması mevcut olup daha kapsamlı çalışmalara intiyaç vardır.

Gastrik polipler belirgin semptoma neden olmayan tesadüfen bulunan oluşumlardır. Malign dönüşümleri nedeniyle özellikle 50 yaş üzeri hastalarda önemlidir. Polipoid lezyonların büyük kısmını oluşturan hiperplastik polipler ve öncül lezyonlarının prekanseröz durumlar olan atrofi ve intestinal metaplazi oranları arasında anlamlı fark saptanmamıştır. Ancak H. pylori oranı, her iki grupta da yüksek saptanmış olmasına karşılık polipoid öncüllerinde anlamlı olarak daha yüksek saptanmıştır. Endoskopi esnasında saptanan lezyonlar tespit edildiklerinde tanı ve displazinin varlığını saptamak için biyopsi alınmalı ya da eksize edilmeli ve uygun hastalar $H$. pylori eradikasyonu için tedavi edilmelidir.

Etik Kurul Onayı: Erzurum Bölge Eğitim ve Araştırma Hastanesi Klinik Araştırmalar Etik Kurulunun 2020/06-67 kararı ile etik kurul onayı alınmıştır.

Çıkar Çatışması: Yazarlar herhangi bir çıkar çatışması beyan etmemişlerdir.

Finansal Destek: Yazarlar finansal destek beyan etmemişlerdir. 


\section{KAYNAKLAR}

1. Şen Oran E, Gençosmanoğlu R. Midenin hiperplastik polipleri: Tanı, tedavi ve izlemde güncel yaklaşımlar. Güncel Gastroenteroloji 2003;7:127-35.

2. Morais DJ, Yamanaka A, Zeitune JM, Andreollo NA. Gastric polyps: a retrospective analysis of 26,000 digestive endoscopies. Arq Gastroenterol 2007;44:14-7.

3. Soytürk M, Akkaya Özdinç S, Sarıoğlu S, et al. Location of endoscopic examination-detected gastric polyps, histopathological types and association with Helicobacter pylori. Endoscopy 2012;20:0104.

4. Zea-Irlarte WL, Sekine I, Itsuno M, et al. Carcinoma in gastric hyperplastic polyps: a phenotypic study. Dig Dis Sci 1996;41:377-86.

5. Dirschmid K, Platz-Baudin C, Stolte M. Why is the hyperplastic polyp a marker for the precancerous condition of the gastric mucosa? Virchows Arch 2006;448:80-4.

6. Turner JR, Odze RD. Polyps of the stomach. In: Odze RD, Goldblum $J R$, Eds. Surgical pathology of the GI tract, liver, biliar tract, and pancreas. 3nd ed. Saunders Elsevier, Philadelphia (Pa), 2015;54078.

7. Karagülle $\mathrm{OO}$, Yavuz E. Assessment of the polypoid lesions deteced in upper gastrointestinal system endoscopies. IKSSTD 2020;12:638.

8. Demiryilmaz I, Albayrak Y, Yilmaz SP. Frequency of various types of gastric polyp. Cumhuriyet Med J 2011;33:209-14.

9. Gencosmanoglu R, Sen-Oran E, Kurtkaya-Yapicier O, et al. Gastric polypoid lesions: analysis of 150 endoscopic polypectomy specimens from 91 patients. World J Gastroenterol 2003;9:2236-9.

10. Sülü B, Demir E, Günerhan $Y$. Endoscopic diagnosis and management of gastric polyps: A clinical study. Turkish journal of Surgery 2012;28:17-20.
11. Carmack SW, Genta RM, Graham DY, Lauwers GY. Management of gastric polyps: a pathology-based guide for gastroenterologists. Nat Rev Gastroenterol Hepatol 2009;6:331-41.

12. Di Giulio E, Lahner E, Micheletti A, et al. Occurrence and risk factors for benign epithelial gastric polyps in atrophic body gastritis on diagnosis and follow-up. Aliment Pharmacol Ther 2005;21:567-74.

13. Abraham SC, Singh VK, Yardley JH, Wu TT. Hyperplastic polyps of the stomach: associations with histologic patterns of gastritis and gastric atrophy. Am J Surg Pathol 2001;25:500-7.

14. Vatansever S, Akpınar Z, Alper E, et al. Gastric polyps and polypoid lesions: Retrospective analysis of 36650 endoscopic procedures in 29940 patients. Turk J Gastroenterol 2015;26:117-22

15. Melton SD, Genta RM. Gastric cardiac polyps: a clinicopathologic study of 330 cases. Am J Surg Pathol 2010;34:1792-7.

16. Archimandritis A, Spiliadis C, Tzivras M, et al. Gastric epithelial polyps: a retrospective endoscopic study of 12974 symptomatic patients. Ital J Gastroenterol 1996;28:387-90.

17. Matysiak-Budnik T, Mégraud F. Helicobacter pylori infection and gastric cancer. Eur J Cancer 2006;42:708-16.

18. Ji F, Wang ZW, Ning JW, et al. Effect of drug treatment on hyperplastic gastric polyps infected with Helicobacter pylori: a randomized, controlled trial. World J Gastroenterol 2006;12:1770-3.

19. Karaman A, Deniz K, Karaman H, et al. Prevalence and histopathological condition of gastric polyps in Central Anatolia. Endoskopi 2011;19:56-8.

20. Zullo A, Hassan C, Romiti A, et al. Follow-up of intestinal metaplasia in the stomach: When, how and why. World J Gastrointest Oncol 2012;4:30-6.

21. Aygün C, Demirci E, Çayırcı M. Prevalence of gastric cancer precursor lesions in patients with dyspepsia. Dicle Med J 2010;37:25-9. 